\title{
Changes in the shape of cloud ice water content vertical structure due to aerosol variations
}

\author{
Steven T. Massie ${ }^{1,3}$, Julien Delanoë ${ }^{2}$, Charles G. Bardeen ${ }^{3}$, Jonathan H. Jiang ${ }^{4}$, and Lei Huang ${ }^{4}$ \\ ${ }^{1}$ Laboratory for Atmospheric and Space Physics, University of Colorado, Boulder, Colorado, USA \\ ${ }^{2}$ LATMOS/IPSL/UVSQ/CNRS, Guyancourt, France \\ ${ }^{3}$ National Center for Atmospheric Research, Atmospheric Chemistry and \\ Modeling, Boulder, Colorado, USA \\ ${ }^{4}$ Jet Propulsion Laboratory, California Institute of Technology, Pasadena, California, USA \\ Correspondence to: Steven T. Massie (steven.massie@lasp.colorado.edu)
}

Received: 17 September 2015 - Published in Atmos. Chem. Phys. Discuss.: 21 January 2016

Revised: 22 April 2016 - Accepted: 1 May 2016 - Published: 19 May 2016

\begin{abstract}
Changes in the shape of cloud ice water content (IWC) vertical structure due to variations in Moderate Resolution Imaging Spectroradiometer (MODIS) aerosol optical depths (AODs), Ozone Monitoring Instrument (OMI) absorptive aerosol optical depths (AAODs), and Microwave Limb Sounder (MLS) CO (an absorptive aerosol proxy) at $215 \mathrm{hPa}$ are calculated in the Tropics during 2007-2010 based upon an analysis of DARDAR IWC profiles for deep convective clouds. DARDAR profiles are a joint retrieval of CloudSat-CALIPSO data. Analysis is performed for 12 separate regions over land and ocean, and carried out applying MODIS AOD fields that attempt to correct for 3-D cloud adjacency effects. The 3-D cloud adjacency effects have a small impact upon our particular calculations of aerosol-cloud indirect effects. IWC profiles are averaged for three AOD bins individually for the 12 regions. The IWC average profiles are also normalized to unity at $5 \mathrm{~km}$ altitude in order to study changes in the shape of the average IWC profiles as AOD increases. Derivatives of the IWC average profiles, and derivatives of the IWC shape profiles, in percent change per 0.1 change in MODIS AOD units, are calculated separately for each region. Means of altitude-specific probability distribution functions, which include both ocean and land IWC shape regional derivatives, are modest, near $5 \%$, and positive to the $2 \sigma$ level between 11 and $15 \mathrm{~km}$ altitude. Similar analyses are carried out for three AAOD and three CO bins. On average, the vertical profiles of the means of the derivatives based upon the profile shapes over land and ocean are smaller for the profiles binned according to AAOD and $\mathrm{CO}$ values,
\end{abstract}

than for the MODIS AODs, which include both scattering and absorptive aerosol. This difference in character supports the assertion that absorptive aerosol can inhibit cloud development.

\section{Introduction}

Uncertainty in aerosol effects upon clouds remains the largest of the global climate forcing uncertainties (Stocker et al., 2013). Tao et al. (2012) discuss the various types of aerosol indirect effects (e.g., effects on cloud droplets and ice particles, reflectance, cloud heights, lifetime, coverage, and precipitation). Though various aerosol indirect effects have been identified, there remains much quantitative uncertainty.

By the cloud invigoration mechanism (Rosenfeld et al., 2008), an increase in aerosol is expected to modify the manner in which vertical and horizontal cloud structure develops in deep convective clouds. The cloud invigoration mechanism is of fundamental importance in regard to aerosol indirect effects upon deep convective clouds. It is expected that the vertical ice water content (IWC), particle radii, and heating rate profiles of a deep convective cloud differ under low and high aerosol optical depths (AODs) due to different initial cloud condensation nuclei $(\mathrm{CCN})$ values in the lower portion of the cloud. A change in the $\mathrm{CCN}$ concentration alters the formation rate and size of liquid droplets, allowing more water to be transported above the freezing level, which leads to a perturbed vertical profile of latent heat release, and sub- 
sequent invigoration of cloud development. This invigoration effect will occur throughout the cloud, changing IWC vertical structure.

The literature of observed and modeled aerosol indirect effects, however, is characterized by a variety of conclusions with differences in even the sign of the effects. For example, Koren et al. (2010) analyzed moderate resolution imaging spectroradiometer (MODIS) AOD and cloud top pressure data for July-August 2007 over the Atlantic west of equatorial Africa for low and high clouds. For high clouds near $370 \mathrm{hPa}$ (i.e., $7 \mathrm{~km}$ altitude, see Fig. 6 of Koren et al., 2010), cloud top pressure changed by $-7 \% / 0.1$ AOD (i.e., cloud top heights increased as AOD increased). In this paper we use $\%$ change per 0.1 AOD units in order to compare the calculations from several studies. Assuming that the cloud top position is dependent upon the location of cloud vertical optical depths near unity, a decrease in cloud top pressure corresponds to moving the optical depth profile upwards in altitude. IWC is then $+7 \% / 0.1$ AOD larger at the position of the higher cloud top. In contrast, Wall et al. (2014) studied congestus (4-8 km altitude range), analyzing 14 years of Tropical Rainfall Measuring Mission (TRMM) radar precipitation features, and 6 years of CloudSat radar reflectivity data. Aerosol Index (AI) data (i.e., AI is the product of MODIS AOD and the MODIS Ångström exponent) were collocated with the TRMM and CloudSat data. TRMM echo-top heights increased with increasing AI over the Amazon and Africa, and decreased over the equatorial Atlantic and southwest United States. Differences in CloudSat maximum reflectivity means of clean and dirty congestus were statistically significant at the $99 \%$ level below $4 \mathrm{~km}$ over the Amazon, and at 4-5 km over Africa, but not at higher altitudes.

It is important to note that changes in particle radius due to changes in aerosol also result in IWC profile perturbations, even in the absence of convective invigoration. Morrison and Grabowski (2011) used a two-dimensional cloud-system resolving model to investigate aerosol indirect effects for pristine, polluted, and highly polluted conditions during a 6-day period of active monsoon conditions. The ensemble calculations indicated a small weakening of convection, higher cloud top heights and anvil ice mixing ratios for the polluted cases. Smaller ice particle sizes and smaller fall velocities perturbed the IWC profiles. Fan et al. (2013) used the NCAR WRF model, coupled to a spectral-bin microphysics code, to simulate deep convective clouds (DCC) for 1 month for three different regions over the tropical western Pacific (i.e., the TWP-International Cloud Experiment), southern China, and over the US southern Great Plains ARM site. They found "that although the widely accepted theory of DCC invigoration due to aerosol's thermodynamic effect (additional latent heat release from freezing of greater amount of cloud water) may work during the growing stage, it is the microphysical effect influenced by aerosols that drives the dramatic increase in cloud cover, cloud top height, and cloud thickness at the mature and dissipation stages by inducing larger amounts of smaller but longer-lasting ice particles in the stratiform/anvils of DCCs, even when thermodynamic invigoration is absent".

Increases in AOD will invigorate for small AODs, though inhibit convection at larger AODs, since larger AODs decrease the amount of sunlight which reaches the surface. Based upon application of a pseudo-adiabatic parcel model, Rosenfeld et al. (2008) estimated that maximum release of convective energy occurs for AODs near 0.3. The contrasting influences of cloud microphysics and radiative processes, and their influence on cloud fraction were parameterized in analytic equations by Koren et al. (2008), and validated by an analysis of MODIS AODs, cloud fractions, and cloud top pressure observed over the Amazon in the dry season. The upper panel of Fig. 2 of Koren et al. (2008) indicates that cloud top pressures are lowest (i.e., cloud top heights are highest) for AODs near 0.4.

It is also possible that absorptive AOD can inhibit cloud development. Ramanathan et al. (2005) used model simulations to study the influence of absorptive aerosol offshore of India. The model aerosol perturbed temperature profile vertical gradients in the first several kilometers near the surface, yielding a stabilizing influence upon cloud development. Ramanathan et al. (2007) deployed small aerial aircraft over the Maldives in 2006 to measure aerosol characteristics during time periods with and without enhanced aerosol amounts. Heating rate calculations indicated that the enhanced aerosol produced a vertical temperature profile that was more stable, and therefore likely inhibited cloud development.

According to the theory, buoyancy increases by the release of latent heat, and decreases when condensate loading (i.e., the weight of liquid or ice in a fluid parcel) increases (see Eqs. (2.50)-(2.53) of Houze, 2014). Lebo and Seinfeld (2011) state that "the aerosol-induced effect is controlled by the balance between latent heating and the increase in condensed water aloft, each having opposing effects on buoyancy." Since changes in buoyancy can be positive or negative, depending upon specific situations in which latent heating or condensate perturbations are dominant, changes in cloud structure IWC likely could be positive or negative as AOD increases.

Lebo and Seinfeld (2011) modeled aerosol effects on deep convection by applying the Weather Research and Forecasting (WRF) model as a cloud resolving model, with separate bulk and bin microphysics schemes. Figure 6 of Lebo and Seinfeld (2011) presents domain averaged liquid and IWC profiles at 2, 4, and $6 \mathrm{~h}$ for "Clean", "Semi-Polluted", and "Polluted" scenarios, with cloud condensation nuclei (CCN) values of 100,200 , and $500 \mathrm{~cm}^{-3}$, respectively. The three IWC profiles for the three $\mathrm{CCN}$ values are equal to each other at 5 (6) $\mathrm{km}$ altitude for the bulk (bin) microphysics schemes, respectively, and then diverge at higher altitudes. This diverging characteristic indicates that the shape of the IWC profile changes as AOD changes. This Figure motivates us to calculate IWC average profiles for individual regions in the Trop- 
ics, and IWC shape profiles, for several AOD bins. The IWC shape profiles are obtained by normalizing the IWC average profiles to unity at $5 \mathrm{~km}$ altitude.

There are noticeable differences in the bulk and bin microphysics model calculations in Fig. 6 of Lebo and Seinfeld (2011). The bulk scheme IWC profiles differ by $-5 \%$ at the IWC peak near $6 \mathrm{~km}$ altitude, indicating a decrease in IWC as aerosol increases, while the bin microphysics IWC profiles differ by $120 \%$ at the IWC peak near $9 \mathrm{~km}$ altitude, indicating a large increase in IWC as aerosol increases. Figure 1 of Rosenfeld et al. (2008), which graphs $500 \mathrm{~nm}$ AOD as a function of CCN, can be used to estimate AODs that correspond to the model $\mathrm{CCN}$ values. The difference in AOD between the Clean and Polluted CCN values is approximately 0.094 . The $120 \%$ increase in IWC therefore translates to an increase in IWC of $127 \%$ per 0.1 AOD. Lebo and Seinfeld (2011) attribute the bulk and bin microphysics model differences to differences in vertical motion and particle size (sedimentation) characteristics of the two microphysical schemes.

Storer and van den Heever (2013) modeled deep convective clouds by running the Regional Atmospheric Modeling System (RAMS) (Cotton et al., 2003) in a 2-D radiativeconvective equilibrium framework. Six CCN loadings between 100 and $3200 \mathrm{~cm}^{-3}$ were applied in separate calculations. After a 60-day initialization, model output was sampled every 5 min during a 10 -day period. They note that early storm updrafts were influenced by increased latent heating, while more mature updrafts were largely influenced by increased drag from condensate loading. Differences in buoyancy curves for "polluted" and "clean" aerosol cases (see Fig. 8 of Storer and van den Heever, 2013) indicate that latent heating effects were numerically smaller, by an order of magnitude, than those due to condensate loading. The number of cloud-top counts, averaged over 10 days, shifted toward higher and medium cloud tops and fewer low cloud tops (see Fig. 1 of Storer and van den Heever, 2013). The freezing level was near $4.4 \mathrm{~km}$, with low, medium, and high cloud tops defined for altitudes less than 4.4, 4.4-10 km, and altitudes greater than $10 \mathrm{~km}$, respectively. On a percentage basis, medium and high cloud top heights increased by approximately 3 and $5 \%$, respectively, between the 100 and $400 \mathrm{~cm}^{-3} \mathrm{CCN}$ values. The 100 and $400 \mathrm{~cm}^{-3} \mathrm{CCN}$ values are closest in value to those used in the Lebo and Seinfeld (2011) calculations discussed above.

Changes in the shape of cloud ice water content vertical structure, and changes in IWC vertical profiles, due to aerosol variations in moderate resolution imaging spectroradiometer (MODIS) aerosol optical depths (AODs), Ozone Monitoring Instrument (OMI) absorptive aerosol optical depths (AAODs), and Microwave Limb Sounder (MLS) CO (an absorptive aerosol proxy) at $215 \mathrm{hPa}$, are calculated in this paper for the Tropics over land and ocean during 20072010 based upon an analysis of DARDAR IWC profiles of deep convective clouds. DARDAR profiles (Delanoë and
Hogan, 2008, 2010) are a joint radar-lidar retrieval using CloudSat radar reflectivity and CALIOP lidar observations at $532 \mathrm{~nm}$. We carry out our calculations over several years (2007-2010), individual regions and seasons, in order to build up statistics. Section 2 discusses the data used in our study, Sect. 3 discusses the Methodology which is applied in a similar manner to the AOD, AAOD and CO data, and results are presented in Sect. 4. A discussion of the results and conclusions are presented in Sect. 5.

\section{Data}

Ice water content vertical profiles are from the v2.1.0 DARDAR (raDAR/liDAR) data archive (http://www.icare. univ-lille1.fr/drupal/archive/) of the ICARE Thematic Center. The DARDAR cloud product is derived using the Varcloud algorithm (Delanoë and Hogan, 2008) and utilizes CloudSat reflectivity, and CALIOP lidar backscatter at $532 \mathrm{~nm}$ to jointly retrieve the properties of ice clouds (e.g., IWC, visible extinction, effective cloud particle radius). There is one DARDAR profile, with a vertical resolution of $60 \mathrm{~m}$, for every CloudSat radar profile and therefore an along-track horizontal resolution of $1.7 \mathrm{~km}$. Cloudsat (Stephens et al., 2002) and the CALIOP lidar (on the CALIPSO satellite, Winker et al., 2010) were launched in tandem in 2006 as part of the A-Train. We analyze data from all months of 2007 through 2010.

The DARDAR retrieval algorithm is discussed in Delanoë and Hogan $(2008,2010)$. The applied optimal estimation technique (see Rodgers (2000) for a general discussion) incorporates up to date aircraft particle size distribution and habit information to formulate forward model look-up tables. The lidar forward model uses a fast radiative transfer code (Hogan, 2006). The combination of $95 \mathrm{GHz}$ CloudSat radar and $532 \mathrm{~nm}$ CALIOP lidar observations provide information on both small and larger ice particles, since CloudSat and CALIOP are sensitive to larger and smaller particles, respectively. Since the lidar is subject to strong attenuation, the radar measurement takes over for thick ice clouds. The radar-lidar overlap region allows one to retrieve simultaneously size and concentration information. For this reason the combination of the two measurements improves the retrieval of cloud properties compared to single instrument retrievals. The DARDAR data focus on ice particles, so our analysis is restricted to altitudes above $5 \mathrm{~km}$.

Deng et al. (2013) found reasonable agreement between CloudSat-CALIPSO (2C-ICE) and DARDAR retrieval products. IWC values from 2B-CWC-RO, 2C-ICE, and DARDAR generally are in good agreement, while 2B-CWCRVOD radii were $40 \%$ larger than the $2 \mathrm{C}$-ICE and DARDAR radii. 
One stated concern in aerosol-indirect effect studies is that it is difficult to measure aerosol optical depths near clouds using nadir view satellite instruments. A cloud away from an observation point scatters light from the cloud towards the nadir observation point, which is then scattered towards the satellite sensor. Varnai and Marshak (2009) quantified how MODIS reflectance is enhanced as a function of distance to the nearest cloud. The reflectance is enhanced by $\sim 10 \%$ when clouds are $5 \mathrm{~km}$ away from clear sky footprints at a wavelength of $0.68 \mu \mathrm{m}$. Zhang et al. (2005) compared AERONET and MODIS MOD04 AODs. They demonstrate that MODIS AODs are enhanced at cloud edges, with differences between MODIS and AERONET AODs increasing as the cloud fraction increases, while the AERONET values stay relatively constant. We address this concern in our calculations by using the latest V6 MODIS aerosol data that include a parameter indicating the average pixel distance from a measured AOD to the nearest cloud feature.

MODIS version 6 MYD04 data files are used to specify daily aerosol optical depth fields. In particular, we utilize the "Optical_Depth_Land_and_Ocean" AOD values at $0.55 \mu \mathrm{m}$, which are specified at $10 \mathrm{~km}$ horizontal spatial resolution. We process the $10 \mathrm{~km}$ AODs into daily data files at $1^{\circ} \times 1^{\circ}$ longitude-latitude resolution for $25^{\circ} \mathrm{S}$ to $25^{\circ} \mathrm{N}$. As discussed by Levy et al. (2013), the Collection 6 (henceforth C6) aerosol retrieval algorithms have made several improvements compared to the C5 data. The C6 "Average_Cloud_Pixel_Distance_Land_Ocean” variable specifies the number of pixel units from an AOD to the nearest cloud pixel. Pixel unit distances are on the order of $0.5 \mathrm{~km}$. We use this variable to calculate separate $1^{\circ} \times 1^{\circ}$ AOD fields for several "cloud screening" cases. For the first case, all AODs are used within a $1^{\circ} \times 1^{\circ}$ grid box if the AOD is between $10^{-3}$ and 3. Another set uses all AODs that are, e.g., 2 or more pixel units from MODIS clouds. Daily $1^{\circ} \times 1^{\circ}$ fields of AODs for 2, 4, and 6 pixel units, and the "all AOD" case, are calculated separately for $25^{\circ} \mathrm{S}$ to $25^{\circ} \mathrm{N}$. As discussed in the next section, the AOD fields are used in separate calculations, for each pixel-distance case, to assess the sensitivity of the calculations to 3-D cloud adjacency effects. The AODs used in our processing are for quality flag 3 (i.e., only the best quality data are used).

Levy et al. (2014) discuss the differences in C6 and C5 Aqua MODIS AODs. C6 AODs increase by 0.05 over the tropical ocean and the Amazon, decrease by -0.05 over the southern oceans and northern mid-latitudes, and increase by 0.02 on a global basis. C6 AODs over land increased by 0.10 over East Asia, vegetation, Africa, Eastern United States, and decreased over the Western United States, South Africa, and semi-arid regions. The correlations of MODIS and AERONET AODs change slightly from 0.928 to 0.937 for the $\mathrm{C} 5$ and $\mathrm{C} 6$ data, respectively. Expected errors for C6 AODs over the ocean are $-0.02(-10 \%)$ and $+0.04(+10 \%)$ and over Land by $\pm(0.05+15 \%)$.

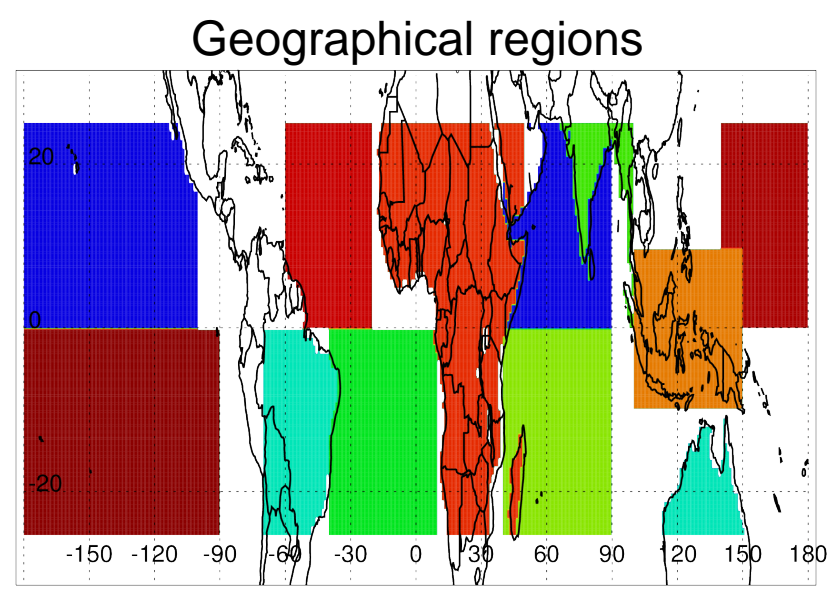

Figure 1. Geographical Tropical regions over land and ocean.

The OMI OMAEROe data are contained in gridded (level 3) hdf files with a resolution of $1 / 4^{\circ} \times 1 / 4^{\circ}$ (http://disc.sci.gsfc.nasa.gov/Aura/data-holdings/OMI/ omaeroe_v003.shtml). These data files utilize for each grid cell the level 2 data that has the shortest sun to sensor path length. The data are derived from a multi-wavelength aerosol retrieval algorithm (Veihelmann et al., 2007; Veihelmann and Veeefkind, 2009) that uses 14 bands and a look up reflectance table, calculated for four aerosol model types (desert dust, biomass burning, volcanic, and weakly absorbing aerosol), size distributions, and aerosol layer altitudes. The level 2 data are calculated by minimizing the differences between observed and model reflectance values.

MLS CO (http://disc.sci.gsfc.nasa.gov/Aura) at $215 \mathrm{hPa}$ is an aerosol proxy (Jiang et al., 2008, 2009). CO is a byproduct of incomplete combustion of biofuels and fossil fuel, and is associated with soot (which absorbs light). $\mathrm{CO}$ is retrieved from microwave radiances in two bands of the $240 \mathrm{GHz}$ radiometer (Livesey et al., 2008). Level 2 version 4.2 profiles have a vertical resolution of $3.5-5 \mathrm{~km}$ in the upper troposphere. We grid CO measurements at $215 \mathrm{hPa}$ into daily $1^{\circ} \times 1^{\circ}$ data files. As discussed in Livesey et al. (2015), $215 \mathrm{hPa}$ is the highest pressure (lowest altitude) for which data applications are recommended. The $215 \mathrm{hPa}$ data have a precision of $19 \mathrm{ppbv}$ and a systematic uncertainty of $\pm 30 \mathrm{ppbv}( \pm 30 \%)$.

\section{Methodology}

Figure 1 presents the various regions in the Tropics for which we calculate average IWC profiles. The 12 regions are either over land or ocean since cloud dynamics differ over land and ocean (Houze, 2014), cloud dynamics likely vary from region to region due to various topographical and surface heating characteristics, and cloud activity peaks at different local times on a regional basis (Liu and Zipser, 2008). We focus on the Tropics in this study to avoid mid-latitude complications 

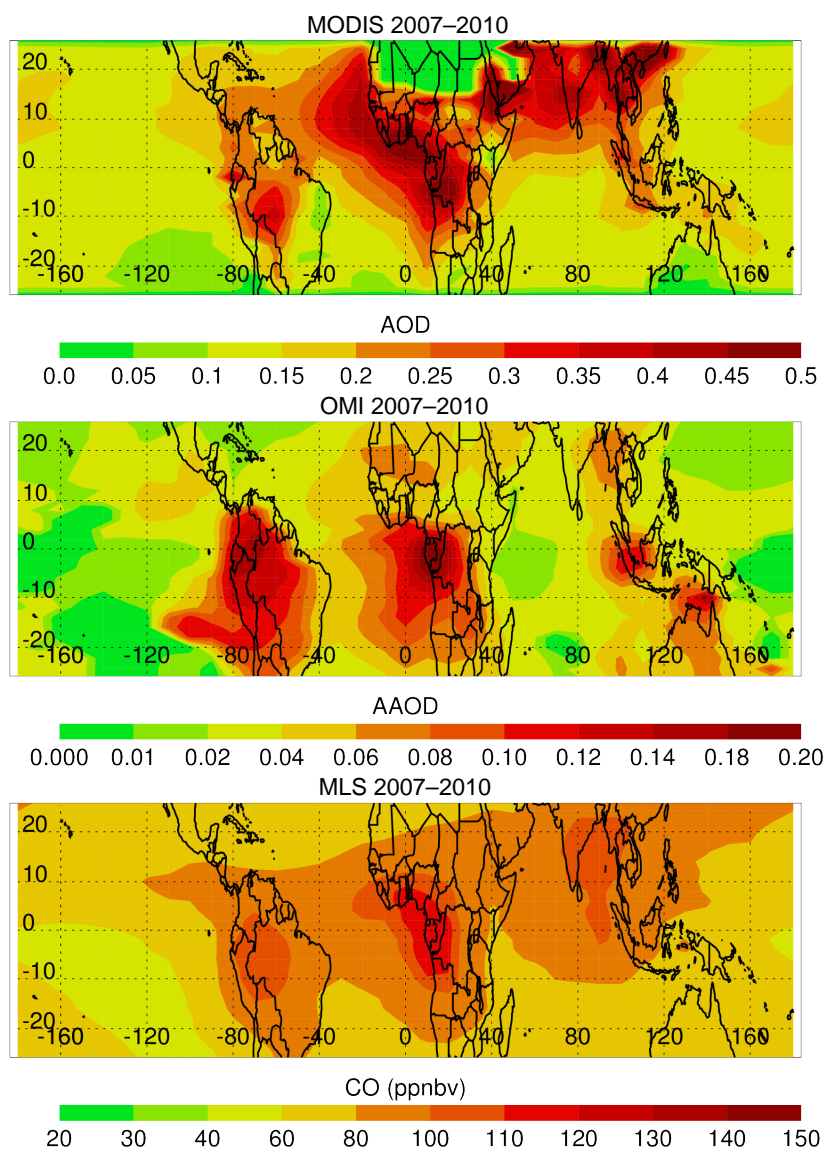

Figure 2. Average MODIS AOD, OMI AAOD, and MLS CO at $215 \mathrm{hPa}$ for $2007-2010$.

due to frontal dynamics. The 12 regions cover most of the Tropics, are limited in longitude, and include as many IWC profiles as possible in order to reinforce the statistics.

The general distribution of MODIS AOD, OMI AAOD, and MLS CO, averaged over all seasons between 2007 and 2010, is presented in Fig. 2. The largest AODs originate from land regions over Africa, South America, Southeast Asia, and Indonesia. There are few $0.55 \mu \mathrm{m}$ AODs over North Africa. This is due to the large surface albedo of desert sands, for which it is difficult for MODIS to detect suspended aerosols. AODs, AAODs, and $\mathrm{CO}$ values are generally larger over land than ocean. Large AODs, AOODs, and CO are observed offshore of Africa due to transport of mainland aerosol to the adjacent ocean areas. Absorptive aerosol is prevalent over South America and Africa due to the prevalence of biomass burning in these regions.

An example of the IWC structure of a deep convective cloud, observed near $111^{\circ} \mathrm{W}$ and $8^{\circ} \mathrm{N}$ on July 10,2007 , is presented in Fig. 3. DARDAR IWC, with original units of $\mathrm{kg} \mathrm{m}^{-3}$ is rescaled for graph clarity purposes. Two hundred and forty individual profiles were measured in this deep convective cloud. In general, IWC increases in value from the top of the cloud downwards, reaches a maximum value,

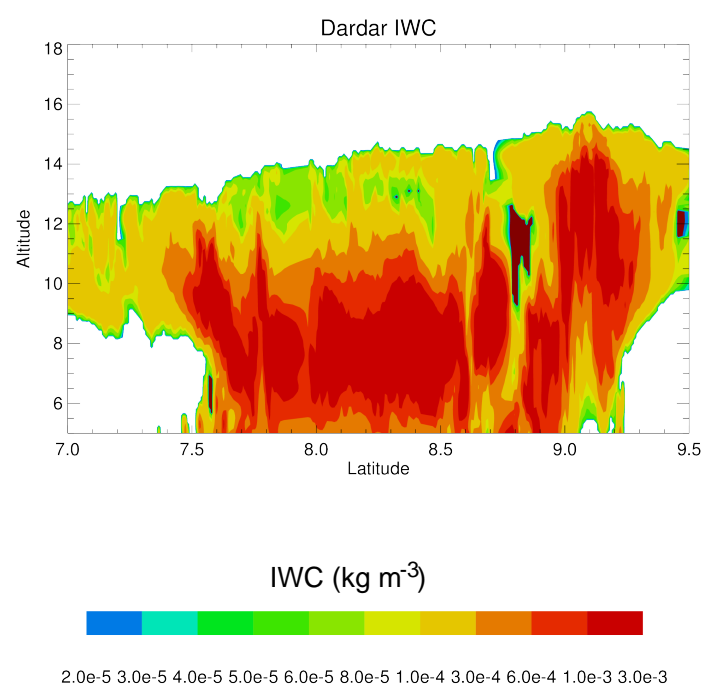

Figure 3. DARDAR IWC structure of a tropical cloudy region observed on 10 July 2007.

$$
\begin{aligned}
& \begin{array}{lllll}
\text { Step } 1 & \text { Step } 2 & \text { Step } 3 & \text { Step } 4 & \text { Step } 5
\end{array} \\
& \begin{aligned}
& \rightarrow \mathrm{IWC}_{\text {reg }} \rightarrow \mathrm{IWC}_{\text {reg,derivatives }} \rightarrow \mathrm{IWC}_{\text {reg,derivative pdfs }} \\
\mathrm{IWC}_{\text {daily }} \rightarrow \mathrm{IWC}_{\text {sum }} & \rightarrow \mathrm{IWC}_{\text {shape }} \rightarrow \mathrm{IWC}_{\text {shape,derivatives }} \rightarrow \mathrm{IWC}_{\text {shape,derivative pdfs }}
\end{aligned}
\end{aligned}
$$

Figure 4. Summary of the processing steps.

then decreases somewhat. For this cloudy region, latitude and height variations in IWC are apparent, since the heights of the top of the cloud and the maximum IWC values vary as a function of latitude.

Based upon the original DARDAR data files, we proceed in several steps, processing both day and night profiles. We first process the DARDAR data into daily files of IWC profiles (i.e., IWC daily). An original profile is retained if the profile has IWC greater than $5 \times 10^{-5} \mathrm{~kg} \mathrm{~m}^{-3}$ and less than $0.05 \mathrm{~kg} \mathrm{~m}^{-3}$ (i.e., near the high end of the retrieval) and if the IWC values are contiguous for two or more kilometers in vertical extent. This Step 1 processing is helpful due to the large data volume (i.e., $1.9 \mathrm{~TB}, 8.2 \times 10^{6}$ profiles for the Tropics) of the original DARDAR data files. This Step and subsequent processing steps are summarized in Fig. 4.

The Step 2 processing of the DARDAR and AOD data produces yearly files of deep convective cloud structure for 2007-2010. Step 1 profiles are used if the vertical depth of the profile is at least $5 \mathrm{~km}$ above $5 \mathrm{~km}$ altitude. Step 1 IWC profiles are collocated with the daily MODIS AOD files to calculate IWCsum profile sums, binned according to AOD, longitude, latitude, aerosol to cloud pixel distance, season, and altitude. 
IWCsum (AOD, longitude, latitude, pixel distance, season, altitude)

$=\Sigma$ IWCdaily

There are three MODIS AOD bins, 72 longitude and 11 latitude bins at $5^{\circ}$ resolution, four cloud-screening cases (for "all AOD", 2, 4, and 6 pixel-distance cases), four seasons, and 131 altitude steps in $0.1 \mathrm{~km}$ increments from 5 to $18 \mathrm{~km}$ altitude. IWCsum units are in $\mathrm{kg} \mathrm{m}^{-3}$. The three AOD bins stated in Table 1 (i.e., 0.01-0.15, 0.15-0.30, 0.30-0.45) were chosen to represent low, medium, and high amounts of AODs (as indicated by inspection of MODIS AOD probability distribution functions, PDFs). The MODIS AOD PDFs (not shown) indicate that there are relatively few MODIS AODs greater than 0.45 . AAOD and $\mathrm{CO}$ bins are also specified in Table 1. The bin ranges were selected from examination of, e.g., $x=$ MODIS AOD vs. $y=$ OMI AAOD scatter diagrams, which indicated the range of OMI AAOD corresponding to each MODIS AOD bin range. The AOD vs. AAOD and AOD vs. CO scatter diagrams places the AOD, AAOD, and $\mathrm{CO}$ calculations on an approximate equal footing.

Step 3 of the processing sorts the IWCsum data into IWCreg regional averages, binned according to AOD, region, aerosol to cloud pixel distance, season, and altitude.

IWCreg (AOD, region, pixel distance, season, altitude)

$=\Sigma$ IWCsum (AOD, longitude, latitude, pixel distance, season, altitude)

This calculation averages data into seven altitude bins of $2 \mathrm{~km}$ vertical extending from 5 to $18 \mathrm{~km}$ altitude. IWCreg units are in $\mathrm{kg} \mathrm{m}^{-3}$. The reason for the vertical binning is to promote as much statistical significance as possible from the averaging process. The number of IWC profiles in a single region and altitude bin varies from less than $10^{3}$ to greater than $9 \times 10^{4}$ since AODs are generally smaller over the oceans and the regions vary in spatial extent.

We also calculate normalized IWC profiles (i.e., IWCshape profiles) based upon the IWCreg profiles by dividing the IWCreg profile by the IWCreg value in the 5 to $7 \mathrm{~km}$ bin range.

IWCshape (AOD, region, pixel distance, season, altitude) = IWCreg (AOD, region, pixel distance, season, altitude)/

IWCreg (AOD, region, pixel distance, season,

altitude from 5 to $7 \mathrm{~km}$ )

The IWCshape array, in dimensionless units, has the same binning as the IWCreg array. The IWCshape profile is of course 1.0 for the $5-7 \mathrm{~km}$ bin, and deviates from unity at higher altitudes, indicating how the shape of the IWC structure progressively changes above $7 \mathrm{~km}$ altitude. As noted above, the calculation of the IWCshape profiles is motivated by the profiles displayed in Fig. 6 of Lebo and Seinfeld (2011) since modeled IWC profiles for the three model $\mathrm{CCN}$ values diverge at altitudes greater than $5 \mathrm{~km}$ altitude.
Table 1. AOD, AAOD, and $215 \mathrm{hPa}$ CO bins used in this study.

\begin{tabular}{cccc}
\hline Bin & AOD & OMI AAOD & MLS CO \\
\hline 1 & $0.01-0.15$ & $0.001-0.01$ & $10-80 \mathrm{ppbv}$ \\
2 & $0.15-0.30$ & $0.01-0.04$ & $80-120$ \\
3 & $0.30-0.45$ & $0.04-0.10$ & $120-150$ \\
\hline
\end{tabular}

Another reason to look at the shape of IWC structure is that observational sampling of a cloudy region for the three AOD bins is not a precisely "controlled" process. A cloudy region has a 3-D IWC structure with 3-D variations in IWC. The CloudSat and CALIPSO sampling of 3-D IWC structures (i.e., a vertical 2-D slice through the cloudy region, with a corresponding set of $1^{\circ} \times 1^{\circ}$ MODIS AODs) is random. One random sampling of a cloudy region could be weighted by more observations with lower IWC values, and another random sampling could be weighted by higher IWC values. If the sampling of 3-D cloudy regions, with respect to low and high regions of IWC, is not consistently similar for the three bins of AOD, then a sampling issue arises. By looking at the shape of the vertical IWC structure one can attempt to mitigate this sampling issue, by putting the IWCreg average profiles for the three AOD bins on a normalized footing. It is reasonable to assume that this sampling issue becomes less of a concern when the number of profiles for a given region and season increases.

In Step 4 of the processing, derivatives are calculated two ways. $\partial \mathrm{IWCreg} / \partial \mathrm{AOD}$ derivatives (henceforth, IWCreg derivatives) are first calculated for each region, season, and pixel-distance AOD field at each of the seven altitude bins. The value of the IWCreg derivative is the average of two derivatives, based upon IWCreg values at the first and second, and first and third, aerosol bins.

$\partial \mathrm{IWCreg} / \partial \mathrm{AOD}$ (region, season, pixel distance, altitude)

$=0.5\{(\operatorname{IWCreg}(2, \ldots)-\operatorname{IWCreg}(1, \ldots)) /$

$(\operatorname{AOD}(2)-\operatorname{AOD}(1))+(\operatorname{IWCreg}(3, \ldots)$

$-\operatorname{IWCreg}(1, \ldots)) /(\operatorname{AOD}(3)-\operatorname{AOD}(1))\}$,

where numbers (e.g., 2) refer to the AOD bin of Table 1, and ... refers to the region, season, pixel distance, and altitude bins. This average derivative is then transformed, for graphical and other purposes, into percent change per 0.1 AOD units by dividing the derivative by the average

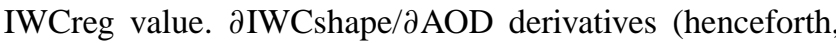
IWCshape derivatives) are then calculated for the seven altitude bins in similar fashion.

Equations (1)-(4) are applied to the IWC profiles using OMI AAOD and MLS CO values, separately, in place of the MODIS AOD data. The transformed AAOD and CO derivatives are in $\%$ per 0.02 AAOD and \% per 100 ppbv units, respectively. The AAOD and $\mathrm{CO}$ derivatives are binned ac- 

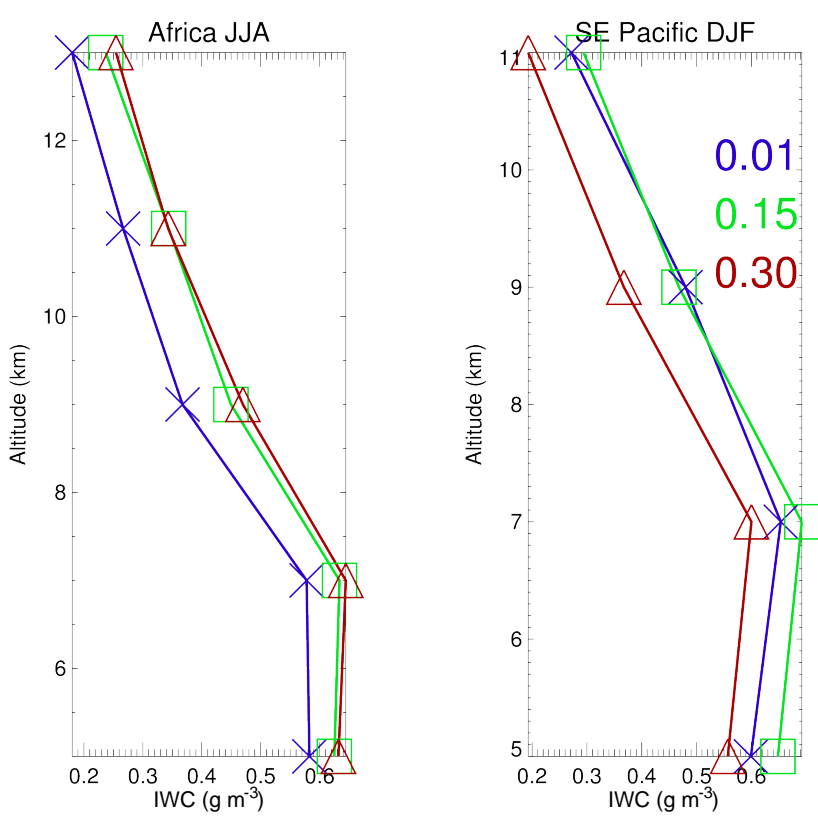

Figure 5. Average IWCreg vertical profiles over SE Pacific during December-January-February and over Africa during June-JulyAugust for MODIS aerosol bins with lower bin limits of $0.01,0.15$, and 0.30 . Data have been averaged into $2 \mathrm{~km}$ bins of vertical altitude.

cording to region, season, pixel distance, and altitude, in the same way as for the AOD derivatives.

In Step 5 of the processing, we place the IWCreg derivatives for the various regions and seasons into PDFs at each of the seven altitude bins. PDFs are constructed separately from the AOD, AAOD, and CO derivatives. Derivatives are included in the PDF if the number of IWC profiles in a derivative is greater than $10^{3}$. (The $10^{3}$ threshold was empirically determined based upon visual examination of individual IWCreg profiles). We calculate the means of the PDFs, standard deviations from the means, and $95 \%(2 \sigma)$ confidence levels of the means of the PDFs. In a similar manner, the IWCshape derivatives are used to calculate the means of PDFs and $95 \%$ confidence limits of the means of the PDFs. As discussed below, we examine and compare the means of the various PDFs.

Finally, an additional separate processing goes back to Step 2 and assigns MODIS AODs at a given $1^{\circ} \times 1^{\circ}$ grid box to the AOD at that position using a randomly chosen day during the year of interest. Ideally, random AODs should yield means of the PDF of the derivatives that are close to zero, since the $\partial \mathrm{IWCreg} / \partial \mathrm{AOD}$ and $\partial \mathrm{IWCshape/ \partial AOD}$ derivatives are reversed in sign if low and high values of AOD are interchanged. We compare the PDF means of this separate processing with those of the previous paragraph.

\section{Results}

Figure 5 illustrates the average vertical structure of IWCreg over Africa during summer (June-July-August) and over the southeast Pacific during winter (December-JanuaryFebruary). The mark at $5 \mathrm{~km}$ specifies the average between 5 and $7 \mathrm{~km}$ altitude, etc. The IWCreg values over Africa increase as AOD increases for nearly every altitude level. In contrast, the IWCreg curves over the southeast Pacific increase from the first to second bin for the 5 to $9 \mathrm{~km}$ range, while decreasing for the first and third aerosol bins. These curves illustrate that derivatives for specific regions and seasons can be either positive or negative.

These curves also indicate that calculations of derivatives need to be confined to specific regions. There are height differences at which a specific IWC value is observed, e.g., $0.3 \mathrm{~g} \mathrm{~m}^{-3}$ occurs at $11 \mathrm{~km}$ over the SE Pacific and at $10.5 \mathrm{~km}$ over Africa for the 0.01-0.15 AOD bin. Global calculations which lump together profiles from different regions mix IWC profiles of different height characteristics, due to regional differences in, e.g., cloud type and/or weather conditions. If the number of regional profiles varies from region to region for a specific AOD bin, and these profiles have different average height characteristics, then the derivatives calculated using the globally lumped profiles are prone to error (since differences in the average regional profiles are related to both AOD effects and regional differences due to cloud type and/or weather conditions).

The impact of cloud adjacency effects upon the AOD fields is illustrated in Fig. 6. Daily MODIS C6 AOD data fields were averaged for $25^{\circ} \mathrm{S}$ to $25^{\circ} \mathrm{N}$ for "all AOD", 2, 4, and 6 pixel-distance cases. On the $x$ axis the AODs correspond to the case when all AODs in the $1^{\circ} \times 1^{\circ}$ grid box are used to define the AOD field. On the $y$ axis is the ratio of the AODs for a particular pixel-distance to the "all AOD" case. The ratios for all of the curves are smallest for the smaller AODs, and increase to larger values as the AODs increase. The AODs are approximately $2 \%$ smaller for the 2 pixeldistance case compared to the "all AOD" case. As more and more AODs are tossed out of the screening process, the AOD averages become progressively smaller than the "all AOD" case, up to $8 \%$ for the 6 pixel-distance case. Unfortunately, the number of nonzero $1^{\circ} \times 1^{\circ}$ grid box AODs decreases for the 4 and 6 pixel-distance cases. Use of the 2 pixel-distance field is more practical than the other cases. Since each AOD bin range in our Step 2 binning processing covers a large range in AOD, a $2 \%$ effect likely places an "all AOD" and, e.g., "2 cloud pixel distance" AOD into the same AOD bin range. It is therefore expected that correction for the cloud adjacency effect, using the three AOD bin ranges mentioned above in Sect. 3, will be of second order in our particular calculations. 


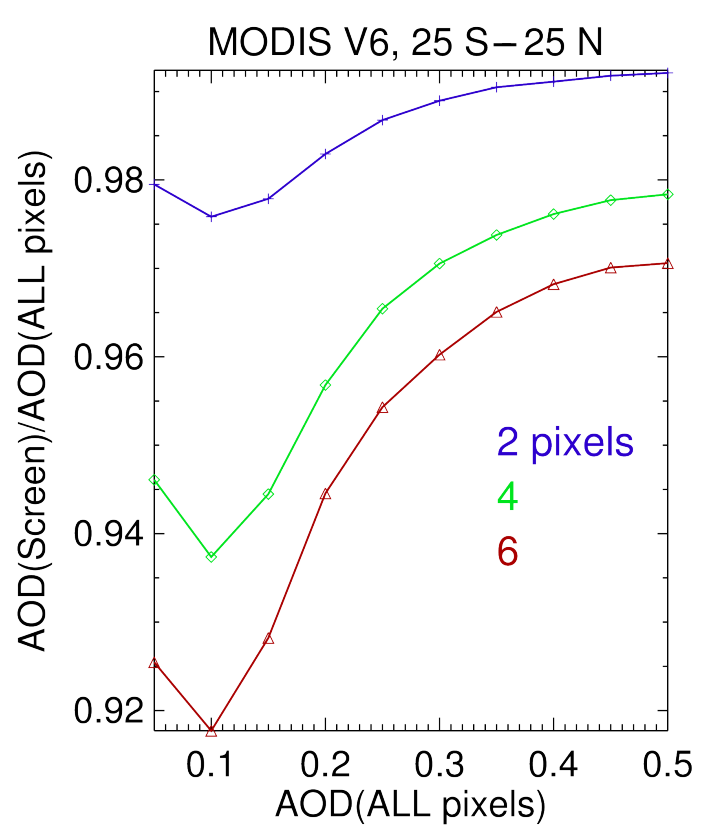

Figure 6. Curves of $1^{\circ} \times 1^{\circ}$ MODIS V6 AOD averages, calculated with and without cloud pixel-distance screening. $x$ axis AOD values are calculated using all MODIS AOD data, and $y$ axis AODs are calculated by averaging AODs such that the AODs in the $1^{\circ} 4 \times 1^{\circ}$ geographical area are at 2, 4, and 6 pixel-distances from clouds. Data from $2007-2010$, for $25^{\circ} \mathrm{S}-25^{\circ} \mathrm{N}$, are used.

In Fig. 7 the statistical distribution of AOD, AAOD, and CO IWCreg derivatives for individual regions and seasons are displayed separately over land and ocean. The $x$ axis indicates the number of individual profiles associated with the derivative of a specific region and season, with IWCreg derivatives on the $y$ axis. As explained in Sect. 3 (Step 4 processing), the value of the IWCreg derivative for a $2 \mathrm{~km}$ altitude bin is the average of two derivatives, based upon IWCreg values at the first and second, and first and third, aerosol bins. The absolute magnitude of the derivatives over land or ocean decreases as the number of profiles increases.

The largest derivatives in the AOD, AAOD, and CO panels are those over mainland India, which are assigned the square symbol in Fig. 7. The India land region has the smallest area of our 12 regions, yet is subject to complicated monsoon dynamics, and with the presence of absorptive aerosols over the Tibetan Plateau, likely subject to the absorptive aerosol "elevated heat pump" mechanism (Lau et al., 2006). Absorptive aerosol above the Tibetan plateau is attributed to provide an elevated heating source which leads to enhanced circulation that will draw air from the surface upwards along the southern flank of the Himalayas. India likely is subject to some of the most complicated aerosol-cloud interactions in the world.

In calculations presented below, we present analyses in which the largest derivatives are included, and excluded, from the calculations. Derivatives are not used in the exclu-
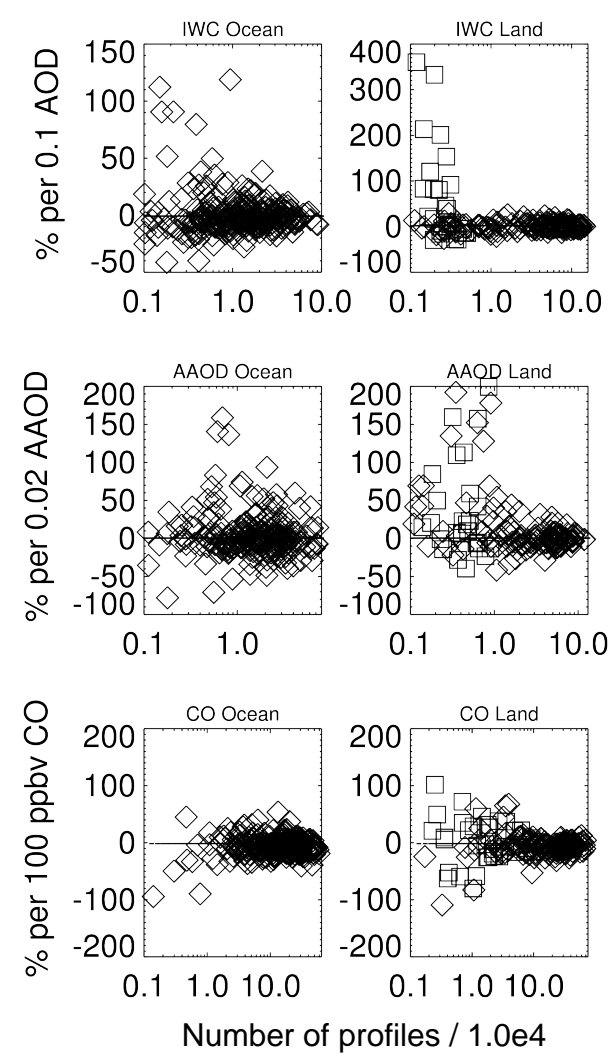

Figure 7. Statistical distribution of IWCreg derivatives between 5 and $15 \mathrm{~km}$ altitude for individual regions and seasons as a function of the number of profiles used to define each derivative. Derivatives over mainland India are assigned a square symbol.

Table 2. Average IWCreg derivatives over ocean and land (in $\% / 0.1$ AOD units) expressed as a function of average pixel-distance values used to derive the AOD fields. Numbers in parenthesis are the numbers of derivatives used to define each average IWCreg derivative.

\begin{tabular}{l|rrr|rrr}
\hline $\begin{array}{l}\text { Altitude } \\
(\mathrm{km})\end{array}$ & \multicolumn{3}{|c|}{ Ocean } & \multicolumn{3}{c}{ Land } \\
\hline \multirow{2}{*}{$13-15$} & 4.4 & 5.1 & -3.8 & 2.8 & 1.7 & 1.7 \\
& $(47$ & 42 & $27)$ & $(31$ & 31 & $28)$ \\
$11-13$ & 0.6 & -0.3 & 2.8 & 23.1 & 23.5 & 15.8 \\
& $(53$ & 53 & $46)$ & $(36$ & 36 & $34)$ \\
$9-11$ & -0.9 & -0.2 & -0.5 & 18.0 & 18.0 & 19.1 \\
& $(54$ & 54 & $48)$ & $(36$ & 36 & $36)$ \\
$7-9$ & -1.7 & -0.2 & 0.5 & 6.5 & 6.8 & 6.6 \\
& $(54$ & 55 & $48)$ & $(36$ & 36 & $36)$ \\
$5-7$ & 0.4 & 0.9 & 1.9 & 1.7 & 1.6 & 1.6 \\
& $(54$ & 54 & $48)$ & $(36$ & 36 & $36)$ \\
\hline
\end{tabular}

sionary calculations if the number of profiles on average are less than 1000 and/or if the derivatives are greater than $100 \%$ per 0.10 AOD, $100 \%$ per $0.02 \mathrm{AAOD}$, or $100 \%$ per $100 \mathrm{ppbv}$ CO. 

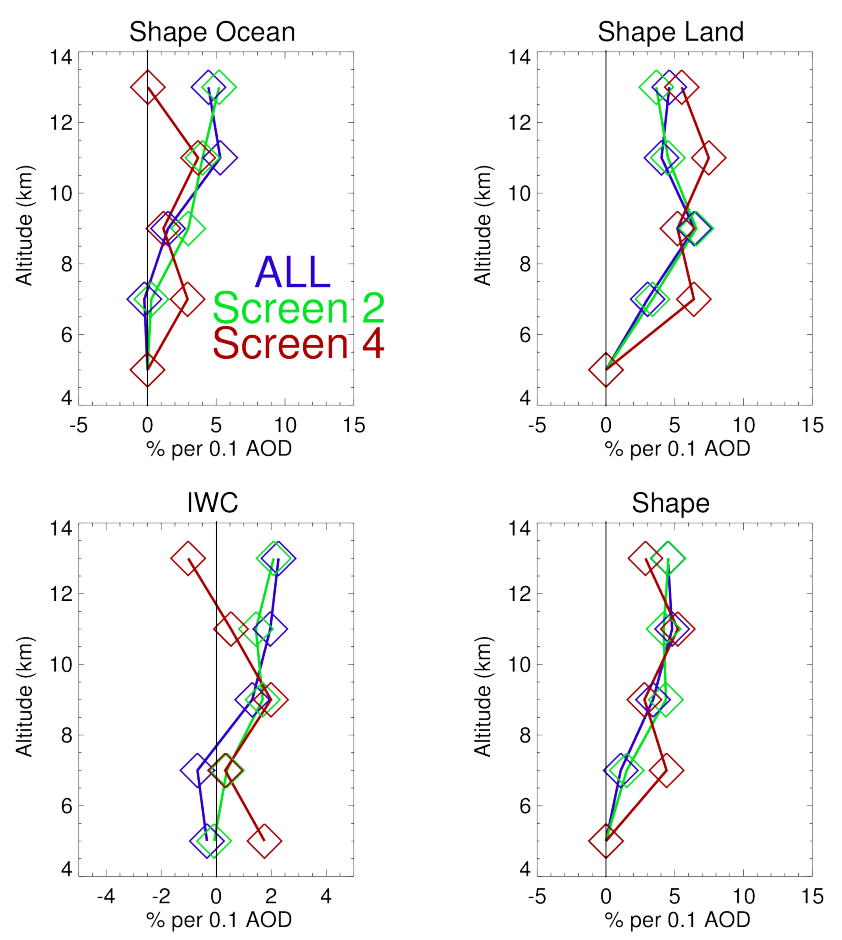

Figure 8. Curves of means of IWCreg and IWCshape PDFs illustrating the sensitivity to the cloud-pixel distance AOD fields. "ALL" refers to the "All AOD" case, and corresponds to curves presented later in the text (i.e., Figs. 11 and 12).

Table 2 presents means of the PDFs for the IWCreg derivatives over land and ocean for the $2 \mathrm{~km}$ altitude bins, expressed as a function of the pixel-distance value. The means are calculated assigning equal weight to each region (i.e., the calculations are not weighted by the number of profiles observed in each region). The number of statistically significant derivatives (i.e., number of separate regions and seasons) that went into the PDF decreases as the cloud pixel-distance value increases (since the number of AODs in the daily $1^{\circ} \times 1^{\circ}$ grid boxes decreases as the pixel-distance value increases). This is most apparent for the 4 pixel-distanced AOD fields. The PDF means in Table 2 are larger over land than the ocean, with fairly small modulation in these means due to pixel-distance choice.

Figure 8 illustrates how the means of curves presented later in the text (i.e., Figs. 11 and 12) are sensitive to the pixel-distance value. The means in Fig. 8 differ from those in Table 2 since the derivatives, used to calculate the curves in Figs. 11 and 12, are those less than $100 \%$ per 0.1 AOD, while all derivatives are included in the Table 2 calculations. The "All AOD" case (i.e., "ALL in Fig. 8) and the Screen 2 (i.e., pixel-distance 2 AOD field) set of means are similar in Fig. 8.

Overall, it is apparent that the 3-D cloud adjacency effect has a fairly small impact upon the means of the PDFs in our calculations. For this reason, we henceforth focus on results

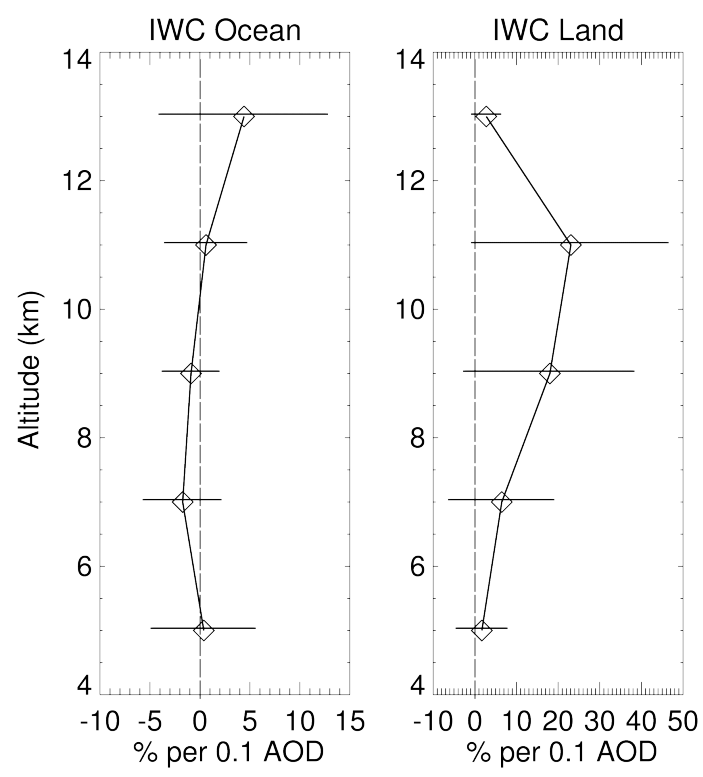

Figure 9. Vertical profiles of the means of the PDFs of IWCreg derivatives for individual regions and seasons based upon DARDAR IWC profiles, and MODIS AOD data for the "all AOD" case. Mean $95 \%$ confidence $(2 \sigma)$ limits are indicated by the horizontal lines. The symbol at $5 \mathrm{~km}$ denotes the average for the $5-7 \mathrm{~km}$ altitude range.

for the "all AOD" case in order to maximize the number of derivatives used in our calculations.

The means of the IWCreg derivative PDFs for the "all AOD" case are presented in Fig. 9 separately for land and ocean data. The $95 \%$ confidence $(2 \sigma)$ limits of the means are given by the horizontal lines. Over the ocean, the left panel of Fig. 9 indicates that the means are consistent with the zero \% per 0.1 AOD line, as the zero $\%$ line falls between the $95 \%$ confidence limits of the means. Over land the means are between 10 and $20 \%$ for the 9 to $13 \mathrm{~km}$ range, also consistent with the $0 \%$ line.

Table 3 presents means of the PDFs for the IWCreg and IWCshape derivatives over land and ocean for the $2 \mathrm{~km}$ altitude bins, for the "all AOD" case. As before (see Table 2) the PDF IWCs derivative means over land are larger than those over the ocean, and the values increase with altitude. In addition, the Rnd columns refer to calculations in which a random day is calculated for each specific day, injecting a random AOD field into the calculations. If AODs are randomly selected from the MODIS AODs, then the means of the PDFs of the IWCshape derivatives are small, though nonzero. We interpret the nonzero values near $2 \%$ as evidence that the means of the cloud dynamic variables (e.g., surface humidity, CAPE, surface temperature, etc.) are different for the various AOD bins. The fact that the differences in the IWCshape and Rnd columns are positive (especially for the observations over land) indicates that the cloud invigoration effect is nonzero and positive. 
Table 3. Average IWCreg and IWCshape derivatives over ocean and land (expressed in \% change in IWC/0.1 AOD units).

\begin{tabular}{l|c|cc|c|cc}
\hline \multirow{2}{*}{$\begin{array}{l}\text { Altitude } \\
(\mathrm{km})\end{array}$} & \multicolumn{3}{|c|}{ Ocean } & \multicolumn{3}{|c}{ Land } \\
\cline { 2 - 7 } & IWCreg & $\begin{array}{c}\text { Shape } \\
\text { IWCshape }\end{array}$ & Rnd & IWCreg & \multicolumn{2}{c}{$\begin{array}{c}\text { Shape } \\
\text { IWCshape }\end{array}$} \\
\hline $13-15$ & 4.4 & 7.4 & 2.0 & 2.8 & 4.6 & 1.6 \\
$11-13$ & 0.6 & 5.3 & 2.8 & 23.1 & 23.8 & 1.2 \\
$9-11$ & -0.9 & 5.4 & 2.2 & 18.0 & 14.5 & 0.1 \\
$7-9$ & -1.7 & -0.2 & 1.2 & 6.5 & 3.0 & -0.7 \\
$5-7$ & 0.4 & 0.0 & 0.0 & 1.7 & 0.0 & 0.0 \\
\hline
\end{tabular}

Rnd - same as IWCshape, with random MODIS AOD values used in the calculation.
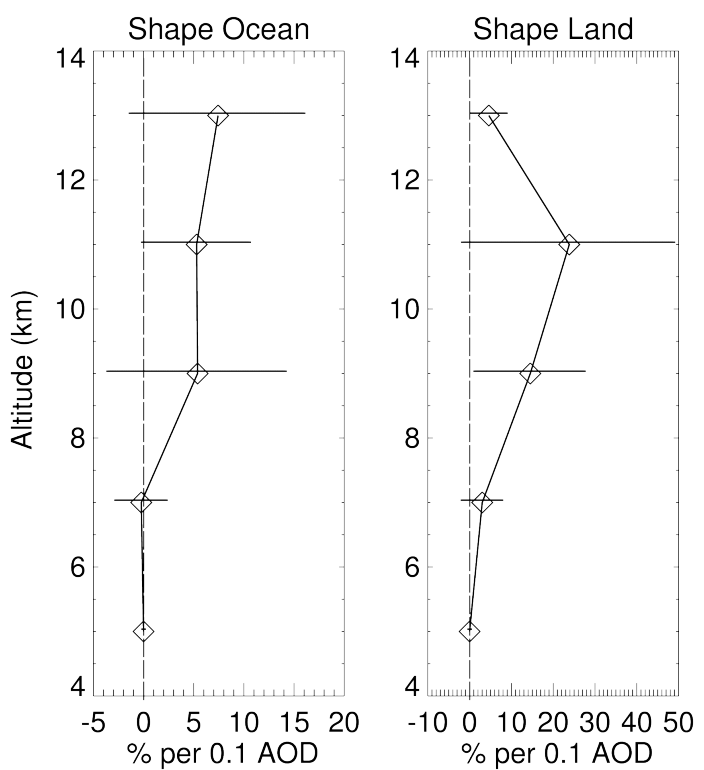

Figure 10. Vertical profiles of the means of the IWCshape regional and seasonal derivatives. MODIS "all AOD" data are used. Mean $95 \%$ confidence $(2 \sigma)$ limits are indicated by the horizontal lines.

Examination of individual derivatives over the ocean and land for the various altitude ranges indicates that most regions have positive and negative derivatives. This is consistent with our statements above in the Introduction that buoyancy is perturbed by both positive (latent heat) and negative (condensate loading) influences. There are more positive ocean IWCreg derivatives north than south of the equator, with the largest annually averaged derivatives over the Northwest and Northeast Pacific, and smallest derivatives over the South Atlantic. Largest annually averaged land derivatives are found over India, South America, and Africa, with smallest derivatives over Australia.

The means of the $\mathrm{IWC}_{\text {shape }}$ derivative PDFs for the "all AOD" case are presented in Fig. 10. Over the ocean and land the means are near 5\% and 10-20\% per 0.1 AOD for the 9 to $13 \mathrm{~km}$ range, respectively. The derivatives are positive to the $2 \sigma$ level for the $9-11$ and $13-15 \mathrm{~km}$ altitude ranges over
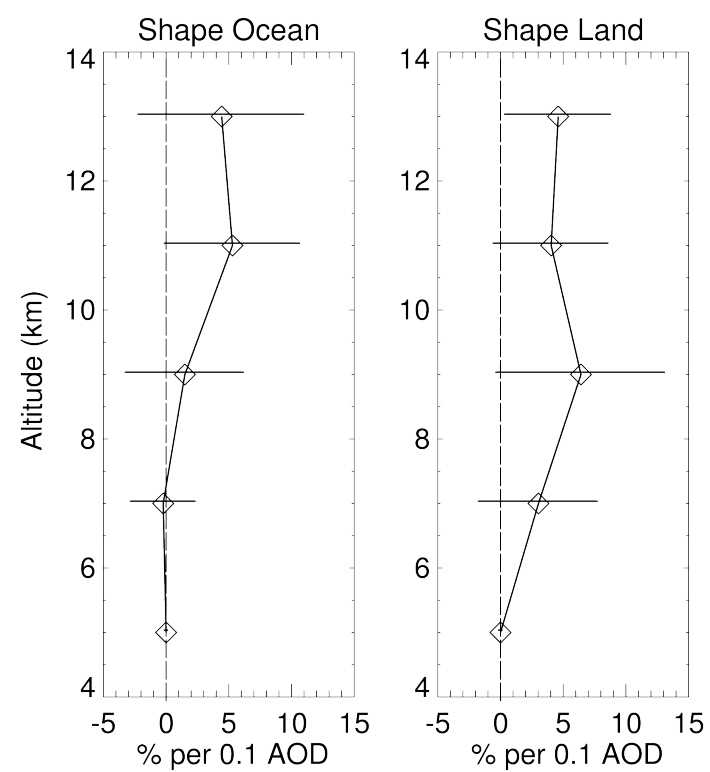

Figure 11. Same as Fig. 9 except that $\mathrm{IWC}_{\text {shape }}$ derivatives less than $100 \%$ per 0.1 AOD are excluded from the averaging process.

land (i.e., the $-95 \%$ confidence limit of the mean value is positive for these two altitude ranges).

As remarked above, in regard to Fig. 7, the India averages have a much smaller number of profiles than for other regions, since the geographical extent of this region is the smallest of the 12 regions. The IWCshape curves, from inspection, are noisier than those of the other regions and the derivatives are substantially larger than those for the other regions. For this reason, it is appropriate to present calculations in which India land derivatives, and those from other regions are excluded, if the number of profiles in an average is less than 1000 and the derivative is greater than $100 \%$ per 0.10 AOD. Figure 11 presents calculations, similar to Fig. 9, except that the large derivatives are excluded from the calculation. Over the ocean and land the means are near 5 and $4 \%$ per 0.1 AOD, respectively, for the $9-13 \mathrm{~km}$ range.

Curves similar to Fig. 11 (not shown) were calculated for each Season of the year. Over land the Winter and Spring 
Table 4. Percent of the observations indicating saturation and inhibition effects as MODIS AODs increase.

\begin{tabular}{l|rr|rr}
\hline \multirow{2}{*}{$\begin{array}{l}\text { Altitude } \\
(\mathrm{km})\end{array}$} & \multicolumn{2}{|c|}{ Saturation } & \multicolumn{2}{c}{ Inhibition } \\
Ocean & Land & Ocean & Land \\
\hline $13-15$ & 44 & 27 & 22 & 13 \\
$11-13$ & 41 & 50 & 26 & 11 \\
$9-11$ & 30 & 50 & 26 & 11 \\
$7-9$ & 33 & 44 & 18 & 39 \\
\hline
\end{tabular}

curves of the IWCshape means have altitude structure similar to Fig. 11 in that the means steadily increase as altitude increases. The Fall land means, however, are all near zero. Over the oceans the means are positive above $11 \mathrm{~km}$ altitude for all four seasons. The land and ocean seasonal means, however, are not statistically significant to the $2 \sigma$ level.

As discussed in the Introduction, AODs are expected to invigorate convection for low AODs, with saturation apparent at larger AODs. These saturation effects start to occur for AODs near 0.30 and 0.40 as calculated by Rosenfeld et al. (2008) and Koren et al. (2008), respectively. These saturation onset AODs correspond to the third AOD range (0.350.45 ) of our calculations. To quantify the percent of observations which are consistent with this saturation scenario, we calculated for each region, season, and altitude, $\Delta \operatorname{IWC}(i, j)$ differences

$\Delta \operatorname{IWC}(i, j)=\operatorname{IWCshape}(i)-\operatorname{IWCshape}(j)$,

where $i$ or $j$ refers to the aerosol bins 1,2, 3 (i.e., the three MODIS aerosol bins in Table 1), respectively. If the first difference $\Delta \operatorname{IWC}(2,1)$ was positive, and the difference $\Delta \operatorname{IWC}(3,2)$ was negative or less than the absolute value of the first difference, then this indicated saturation. With regards to inhibition, this scenario corresponds to the case in which the $\Delta \operatorname{IWC}(2,1)$ and $\Delta \operatorname{IWC}(3,2)$ values are both negative. Table 4 presents the percentages for which these two scenarios appeared in our calculations based upon the MODIS data. The saturation scenario occurred approximately twice as often as the inhibition scenario. These percentages are for "ideal" outcomes in which both $\triangle$ IWC values are used to identify one scenario or the other.

Figure 12 displays the means of PDFs specified by combining the land and ocean IWCshape derivatives, excluding the largest derivatives, to obtain a Tropical average. The means of the shape derivatives are near $5 \%$ per $0.1 \mathrm{AOD}$ (as expected from Fig. 11), and positive to the $2 \sigma$ level in the 11 to $15 \mathrm{~km}$ altitude range. Also displayed in Fig. 12 are means calculated using the IWCreg derivatives, again excluding the largest derivatives. The means are positive above $9 \mathrm{~km}$ altitude, but not statistically significant at the $2 \sigma$ level. The mean of the IWCreg derivatives in the 5-7 km altitude range is nonzero (i.e., 0.04) but very small.

Another way to look at the derivatives is by graphing PDFs of the derivatives. Figure 13 presents PDFs of the IWCshape
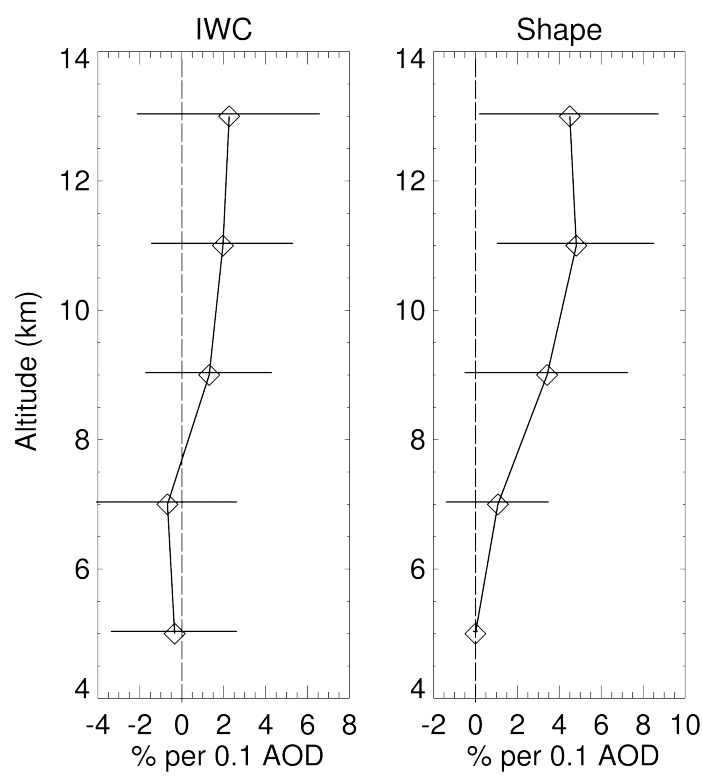

Figure 12. Means of PDFs of IWCreg and IWCshape derivatives over ocean and land, excluding derivatives greater than $100 \%$ per 0.1 AOD. Mean $95 \%$ confidence limits, given by the horizontal lines, indicate that IWCshape means are positive to the $2 \sigma$ level for the $11-15 \mathrm{~km}$ altitude range.

derivatives for the AOD, AAOD, and CO data. Derivatives over the ocean and land regions (excluding the largest derivatives) were aggregated for the 7-13 altitude range. All PDFs have a main Gaussian-like distribution, with several smaller contributions outside of the primary distribution. Averages of the PDFs are indicated at the top of the panels. The arithmetic means of the PDFs are less for the AAOD and CO data than for the AOD data, with positive means for the AOD data, and negative means especially for the $\mathrm{CO}$ data. These results are supportive of the assertion that absorptive aerosol tends to inhibit cloud development.

Figure 14 presents average IWCreg derivatives for AOD, $\mathrm{AAOD}$, and $\mathrm{CO}$ data over ocean and land for all regions, excluding the largest derivatives. For legibility purposes, $1 \sigma$ confidence limits of the determination of the means are given by the horizontal lines. The $\mathrm{CO}$ means over land and ocean are negative for the $7-15 \mathrm{~km}$ altitude range.

Finally, Fig. 15 is similar to Fig. 14 except that average shape derivatives are presented. The AAOD and CO shape derivative means are less than the AOD means both over ocean and land for the $9-15 \mathrm{~km}$ altitude range. These results are supportive of the assertion that absorptive aerosol tends to inhibit cloud development. It is notable in both Figs. 14 and 15 that the size of the mean derivatives are fairly small, with values mostly between -15 and $5 \%$. 

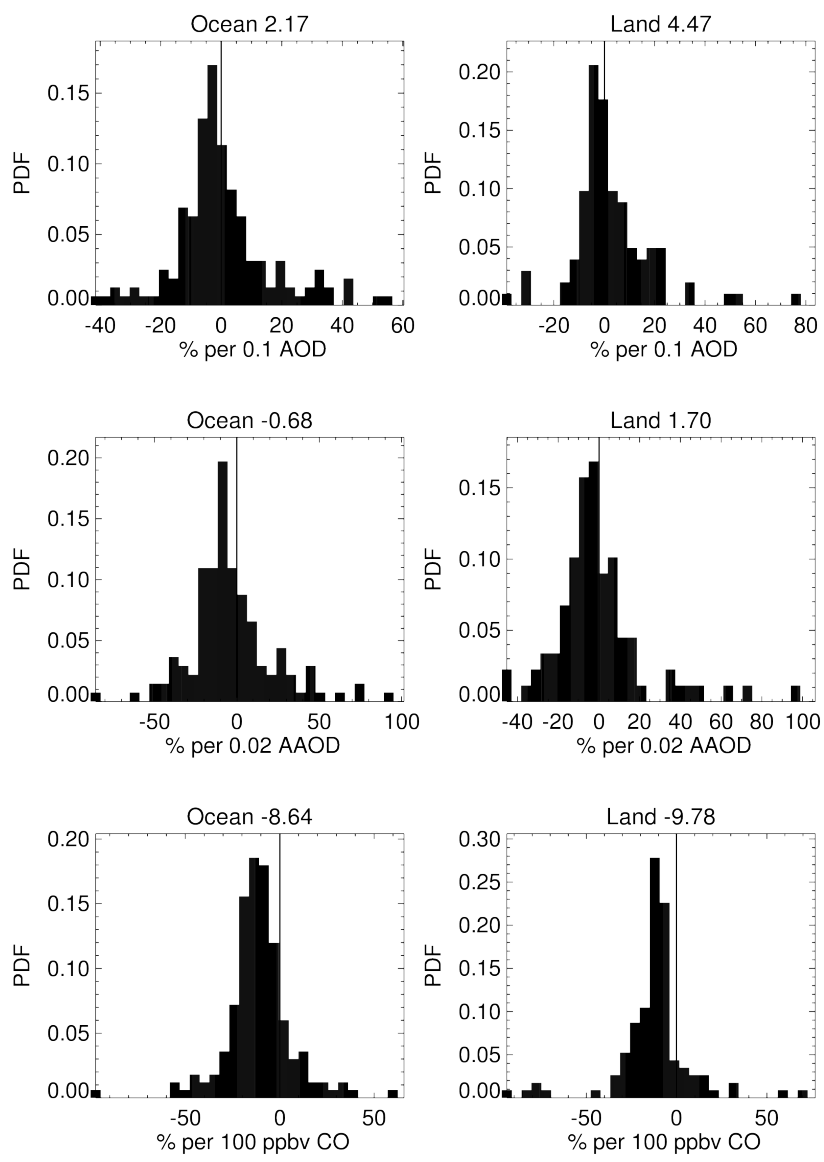

Figure 13. Histograms of IWCshape derivatives for AOD, AAOD, and $\mathrm{CO}$ bins, when the derivatives are less than $100 \%$ per 0.10 AOD, $100 \%$ per 0.02 AAOD, and $100 \%$ per 100 ppbv CO, respectively. Means of the distributions are indicated by the numbers in each panel's title. Averages pertain to the $7-15 \mathrm{~km}$ altitude range.

\section{Discussion}

IWC increases slightly on average for deep convective clouds above the freezing level as AODs increase. The Tropical average means (Fig. 12), calculated using combined ocean and land IWCshape derivatives (excluding the largest derivatives) are near $5 \%$ per 0.1 AOD above $9 \mathrm{~km}$ altitude, and positive to the $2 \sigma$ level in the $11-15 \mathrm{~km}$ range. The $5 \%$ per $0.1 \mathrm{AOD}$ value is similar to the previously determined $7 \%$ per 0.1 AOD value observed over the equatorial Atlantic region (corresponding to the cloud top pressure data of Fig. 6 from Koren et al., 2010), and similar to the 3-5\% increase in medium and high cloud tops calculated by Storer and van den Heever (2013), but substantially less than the $\sim 127 \% / 0.1$ AOD change in the IWC profile indicated by the bin microphysics calculations presented in Fig. 6 of Lebo and Seinfeld (2011).

As discussed above, the IWCreg average profiles are calculated without normalization at $5 \mathrm{~km}$ altitude. The IWCreg means in Fig. 12 are positive above $9 \mathrm{~km}$ but not statistically
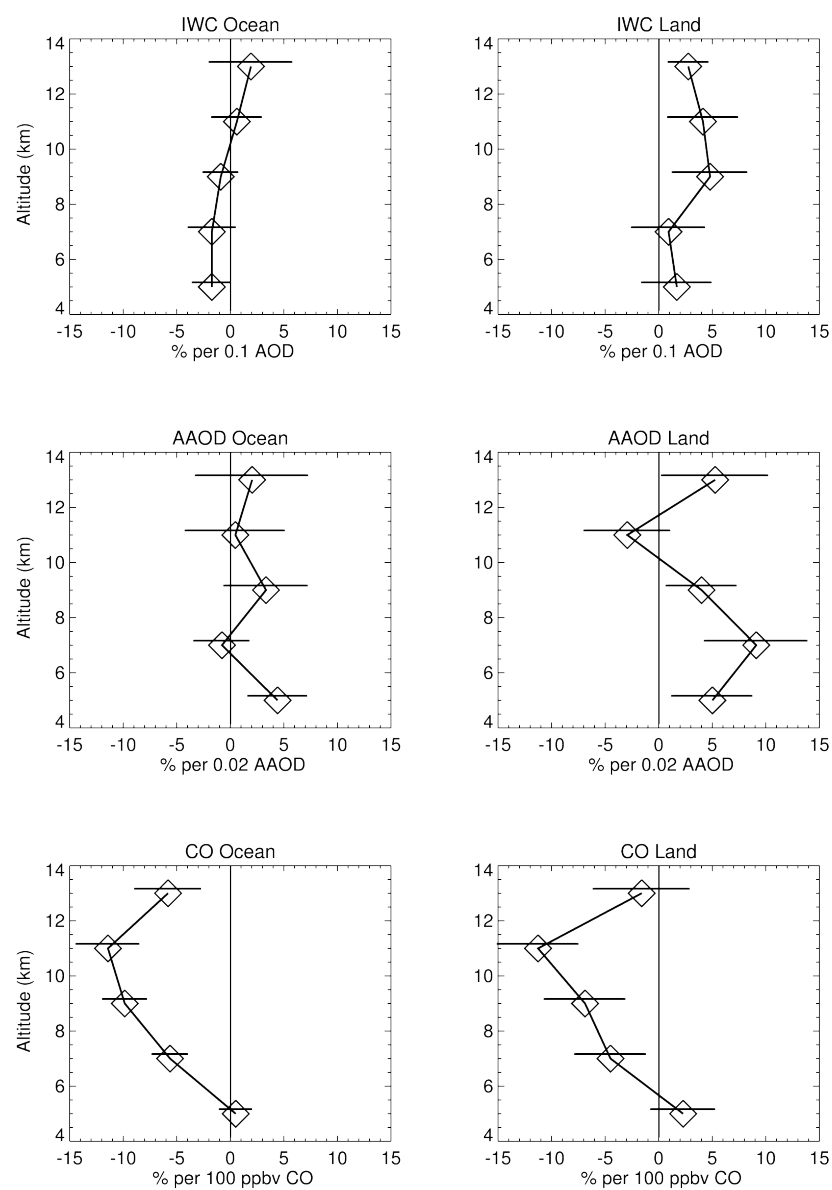

Figure 14. Average IWCreg derivatives over ocean and land for AOD, AAOD, and CO. Derivatives were used when they were less than $100 \%$ per 0.10 AOD, $100 \%$ per 0.02 AAOD, and $100 \%$ per $100 \mathrm{ppbv}$ CO. Confidence limits $(1 \sigma)$ of the determination of the means are indicated by the horizontal bars.

significant at the $2 \sigma$ level. The lack of statistical significance is similar to the conclusions of Wall et al. (2014). One is struck by the fact that our study and that of Wall et al. (2014) both yield inconclusive aerosol indirect effects when many years of data are processed.

Figure 7 imparts an important lesson - the scatter in the measured derivatives decreases as the number of observed profiles in the various regions increases. We interpret Fig. 7 as follows. Changes in IWC vertical structure are due to both aerosol and cloud dynamic influences. For a specific region, a relatively small number of profiles will not likely sample the PDFs of all variables (aerosol and cloud dynamic variables such as surface and $500 \mathrm{hPa}$ relative humidity, CAPE, wind shear, etc) as completely as for the case in which a larger number of profiles are considered. Differences in the average IWCreg profiles at different AODs can be due to differences in cloud dynamic differences, to a greater extent than to the AOD difference, depending upon circumstance, if the number of observed profiles is relatively small. A negative (or 

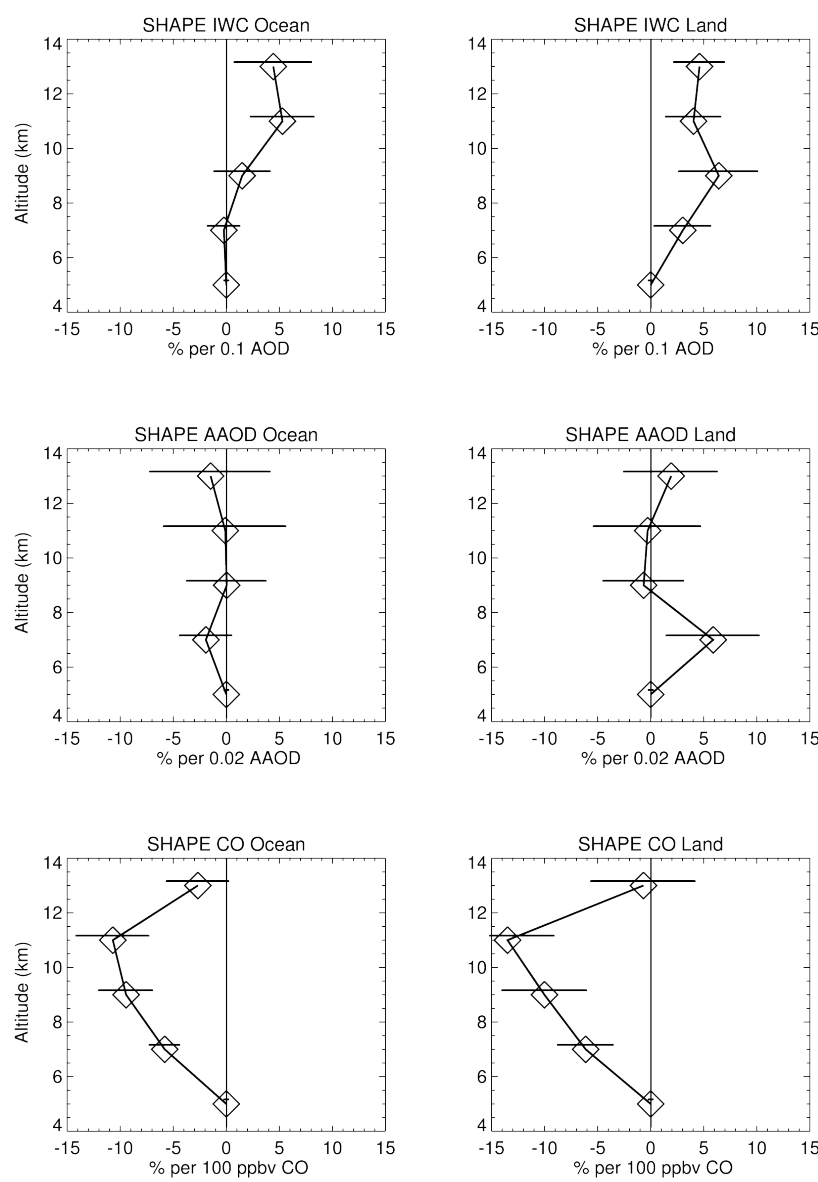

Figure 15. Average IWCshape derivatives over ocean and land for AOD, AAOD, and CO. Derivatives were used when they were less than $100 \%$ per $0.10 \mathrm{AOD}, 100 \%$ per $0.02 \mathrm{AAOD}$, and $100 \%$ per $100 \mathrm{ppbv}$ CO. Confidence limits $(1 \sigma)$ of the determination of the means are indicated by the horizontal bars.

large positive) derivative could be due to a change in cloud dynamic influences and not the AOD change. In addition, the CloudSat/CALIPSO observational 2-D "curtains" slice through a cloudy region. If the sampling of 3-D cloudy regions with respect to low and high regions of IWC is not consistently similar for the, e.g., three bins of AOD, then a sampling issue arises. This sampling consideration becomes less of an issue when the number of observed profiles increases.

Interest in the cloud invigoration process is of course important due to its consequences in regard to the radiative effects of aerosol indirect effects - perturbations in cloud vertical structure due to changes in aerosol translate into perturbations in the radiative effects of clouds upon climate. Understanding the effects of aerosols upon cloud structure is a necessary step towards understanding the radiative effects. Global calculations which average regional and seasonal perturbations of cloud structure over many years are of interest since they yield a grand ensemble average that fully samples the PDFs of the aerosol and cloud dynamic variables.

It is apparent from our calculations that both invigoration processes (Rosenfeld et al., 2008; Koren et al., 2008) and inhibition processes (Ramanathan et al., 2005, 2007) are expressed in our long-term derivatives which indicate that IWC can both increase or decrease as AOD increases. Changes in MODIS IWCshape profiles did indicate saturation effects as discussed by Koren et al. (2008). Saturation effects, in which an increase in IWC is followed by a small increase or decrease in IWC, was present $32 \%$ of the time (the average of the 1st and 2nd columns of Table 4). The means of the PDFs presented in Fig. 13, and the means of the IWCshape derivatives presented in Fig. 15 are also supportive of the assertion that absorptive aerosol can inhibit cloud development. Inhibition effects were present $17 \%$ of the time (the average of 3rd and 4th columns of Table 4). The saturation scenario for MODIS data occurred approximately twice as often as the inhibition scenario.

Cloud adjacency (i.e., 3-D radiative transfer) issues are real, but the impact in our particular calculations is a second order effect. The 3-D cloud adjacency effects appear not to be a major impediment in regard to calculation of aerosol-cloud indirect effects, if the AOD bin ranges are fairly wide compared to the size of the 3-D effect (see Fig. 6). The variations in the IWCreg land derivatives in Table 2 for the "all AOD", 2 , and 4 pixel-unit cases is smaller than the altitude variations in the derivatives. We place an AOD into one of three AOD bin ranges. A $2 \%$ AOD correction (see Fig. 6) due to cloud adjacency effects does not likely move the AOD from one bin range to another. As remarked above, the number of $1^{\circ} \times 1^{\circ}$ AODs decrease as the pixel-distance unit increases. With the "all AOD" and 2 pixel-distance AODs giving similar derivatives over land in the right-hand portion of Table 2, and with the similarity in the curves presented in Fig. 8 for the three screening cases, the necessity to apply the pixel-distance correction is debatable.

In conclusion, the literature of observed and modeled aerosol-cloud indirect effects is characterized by a range of results of different signed outcomes, including this study. This is due to the fact that numerous variables and many other physical considerations can influence whether a positive or negative effect is measured. In Fig. 15 there is a stark contrast between the positive AOD derivatives above $9 \mathrm{~km}$ altitude, and the negative $\mathrm{CO}$ derivatives. A portion of the contrasting positive and negative results reported in the literature is likely due to whether or not absorptive aerosol is absent or present in a particular set of observations.

\section{Data availability}

DARDAR data were provided by CNES, and we thank the ICARE Data and Services Center (http://www.icare. univ-lille1.fr) for providing access to the data used in this study. OMI OMAEROe and MLS CO data were provided 
by the NASA Goddard Earth Sciences Data and Information Services Center (http://disc.sci.gsfc.nasa.gov/Aura/ data-holdings/OMI/omaeroe_v003.shtml and http://disc.sci. gsfc.nasa.gov/Aura, respectively).

Acknowledgements. The work discussed in this paper is supported by NASA Grants NNX14AL55G and NNX14AO85G. The National Center for Atmospheric Research (NCAR) is supported by the National Science Foundation. We also acknowledge the support by the Jet Propulsion Laboratory, California Institute of Technology, under contract with NASA.

Edited by: Q. Fu

\section{References}

Cotton, W., Pielke Sr., R. A., Walko, R. L., Liston, G. E., Tremback, C. J., Jiang, H., McAnelly, R. L., Harrington, J. Y., Nicholls, M. E., Carrio, G. G., and McFadden, J. P.: RAMS 2001: Current status and future directions, Meteorol. Atmos. Phys. 82, 5-29, 2003.

Delanoë, J. and Hogan, R. J.: A variational scheme for retrieving ice cloud properties from combined radar, lidar, and infrared radiometer, J. Geophys. Res., 113, D07204, doi:10.1029/2007JD009000, 2008.

Delanoë, J. and Hogan, R. J.: Combined CloudSat-CALIPSOMODIS retrievals of the properties of ice clouds, J. Geophys. Res., 115, D00H29, doi:10.1029/2009JD012346, 2010.

Deng, M., Mace, G. G., Wang, Z., and Lawson, P. R.: Evaluation of Several A-Train Ice Cloud Retrieval Products with In Situ Measurements Collected during the SPARTICUS Campaign, J. Appl. Meteorol. Clim., 52, 1014-1030, 2013.

Fan, J., Leung, L. R., Rosenfeld, D., Chen, Q., Li, Z., Zhang, J., and Yan, H.: Microphysical effects determine macrophysical response for aerosol impacts on deep convective clouds, P. Natl. Acad. Sci., 110, E4581-E4590, 2013.

Hogan, R. J.: Fast approximate calculation of multiply scattered lidar returns, Appl. Optics, 45, 5984-5992, 2006.

Houze, R.: Cloud Dynamics, Elsevier, Amsterdam, the Netherlands, 2014.

ICARE Thematic Center: v2.1.0 DARDAR data, Ice water content vertical profiles, available at: http://www.icare.univ-lille1.fr/ drupal/archive, last access: 10 May 2016.

Jiang, J. H., Su, H., Schoeberl, M., Massie, S. T., Colarco, P., Platnick, S., and Livesey, N. J.: Clean and polluted clouds: relationships among pollution, ice cloud and precipitation in South America, Geophys. Res. Lett., 35, L14804, doi:10.1029/2008GL034631, 2008.

Jiang, J. H., Su, H., Massie, S. T., Colarco, P. R., Schoeberl, M. R., and Platnick, S: Aerosol-CO relationship and aerosol effect on Ice cloud particle size: Analyses from Aura Microwave Limb Sounder and Aqua Moderate Resolution Imaging Spectroradiometer observations, J. Geophys. Res., 114, D20207, doi:10.1029/2009JD012421, 2009.

Koren, I., Martins, J. V., Remer, L. A., and Afargan, H.: Smoke invigoration versus inhibition of clouds over the Amazon, Science, 321, 946-949, 2008.
Koren, I., Feingold, G., and Remer, L. A.: The invigoration of deep convective clouds over the Atlantic: aerosol effect, meteorology or retrieval artifact?, Atmos. Chem. Phys., 10, 8855-8872, doi:10.5194/acp-10-8855-2010, 2010.

Lau, K. M., Kim, M. K., and Kim, K. M.: Asian summer monsoon anomalies induced by aerosol direct forcing: the role of the Tibetan Plateau, Clim. Dynam., 26, 855-864, doi:10.1007/s00382006-0114-z, 2006.

Lebo, Z. J. and Seinfeld, J. H.: Theoretical basis for convective invigoration due to increased aerosol concentration, Atmos. Chem. Phys., 11, 5407-5429, doi:10.5194/acp-11-5407-2011, 2011.

Levy, R. C., Mattoo, S., Munchak, L. A., Remer, L. A., Sayer, A. M., Patadia, F., and Hsu, N. C.: The Collection 6 MODIS aerosol products over land and ocean, Atmos. Meas. Tech., 6, 29893034, doi:10.5194/amt-6-2989-2013, 2013.

Levy, R. C., Mattoo, S., Munchak, L. A., Kleidman, A. R., Patadia, F., and Gupta, P: MODIS Atmosphere Team Webinar Series\#2: Overview of Collection 6 Dark-Target aerosol product, available at: http://modis-atmos.gsfc.nasa.gov/products_C006update. html (last access: 10 May 2016), 2014.

Liu, C. and Zipser, E. J.: Diurnal cycles of precipitation, clouds, and lightning in the tropics from 9 years of TRMM observations, Geophys. Res. Lett., 35, L04819, doi:10.1029/2007GL032437, 2008.

Livesey, N. J., Filipiak, M. J., Froidevaux, L., Read, W. G., Lambert, A., Santee, M. L., Jiang, J. H., Pumphrey, H. C., Waters, J. W., Cofield, R. E., Cuddy, D. T., Daffer, W. H., Drouin, B. J., Fuller, R. A., Jarnot, R. F., Jiang, Y. B., Knosp, B. W., Li, Q. B., Perun, V. S., Schwartz, M. J., Snyder, W. V., Stek, P. C., Thurstans, R. P., Wagner, P. A., Avery, M., Browell, E. V., Cammas, J.-P., Christensen, L. E., Diskin, G. S., Gao, R.-S., Jost, H.-J., Loewenstein, M., Lopez, J. D., Nedelec, P., Osterman, G. B., Sachse, G. W., and Webster, C. R.: Validation of Aura Microwave Limb Sounder $\mathrm{O}_{3}$ and $\mathrm{CO}$ observations in the upper troposphere and lower stratosphere, J. Geophys. Res., 113, D15S02, doi:10.1029/2007JD008805, 2008.

Livesey, N. J., Read, W. G., Wagner, P. A., Froidevaux, L., Lambert, A., Manney, G. L., Mill'an, L. F., Pumphrey, H. C., Santee, M. L., Schwartz, M. J., Wang, S., Fuller, R. A., Jarnot, R. F., Krosp, B. W., and Martinez, E.: Version 4.2x Level 2 data quality and description document. JPL D-33509 Rev. A, available at: http:// mls.jpl.nasa.gov/data/v4-2_data_quality_document.pdf (last access: 10 May 2016), 2015.

Morrison, H. and Grabowski, W. W.: Cloud-system resolving model simulations of aerosol indirect effects on tropical deep convection and its thermodynamic environment, Atmos. Chem. Phys., 11, 10503-10523, doi:10.5194/acp-11-10503-2011, 2011.

NASA Goddard Earth Sciences Data and Information Services Center data archive: v3 OMI OMAEROe data, absorptive aerosol optical depths, available at: http://disc.sci.gsfc.nasa.gov/Aura/ data-holdings/OMI/omaeroe_v003.shtml, last access: 10 May 2016.

NASA Goddard Earth Sciences Data and Information Services Center data archive: v4 MLS CO data, carbon monoxide mixing ratios, available at: http://disc.sci.gsfc.nasa.gov/Aura, last access: 10 May 2016.

Ramanathan, V., Chung, C., Kim, D., Bettge, T., Buja, L., Kiehl, J. T., Washington, W. M., Fu, Q., Sikka, D. R., and Wild, M.:Atmospheric brown clouds: Impacts on South Asian climate 
and hydrological cycle, P. Natl. Acad. Sci. USA, 102, 53265333, doi:10.1073/pnas.0500656102, 2005.

Ramanathan, V., Ramana, M.m V., Roberts, G., Kim, D., Corrigan, C., Chung, C., and Winker, D.: Warming trends in Asia amplified by brown cloud solar absorption, Nature, 448, 575-579, doi:10.1038/nature06019/, 2007.

Rodgers, C. D: Inverse Methods for Atmospheric Sounding, World Scientific, Singapore, 2000.

Rosenfeld, D., Lohmann, U., Raga, G. B, O’Dowd, C. D, Kulmala, M., Fuzzi, S., Reissell, A., and Andreae, M. O.: Flood or drought: How do aerosols affect precipitation?, Science, 321, 1309-1313, doi:10.1126/science.1160606, 2008.

Stephens, G. L., Vane, D. G., Boain, R. J., Mace, G. G., Sassen, K., Wang, Z., Illingworth, A. J., O'Connor, E. J., Rossow, W. B., Durden, S. L., Miller, S. D., Austin, R. T., Benedetti, A., Mitrescu, C., and The CloudSat Science Team: THE CLOUDSAT MISSION AND THE A-TRAIN, B. Am. Meteorol. Soc., 83, 1771-1790, doi:10.1175/BAMS-83-12-1771, 2002.

Stocker, T. F., Qin, D., Plattner, G.-K., Alexander, L. V., Allen, S. K., Bindoff, N. L., Bréon, F.-M., Church, J. A., Cubasch, U., Emori, S., Forster, P., Friedlingstein, P., Gillett, N., Gregory, J. M., Hartmann, D. L., Jansen, E., Kirtman, B., Knutti, R., Krishna Kumar, K., Lemke, P., Marotzke, J., Masson-Delmotte, V., Meehl, G. A., Mokhov, I. I., Piao, S., Ramaswamy, S. V., Randall, D., Rhein, M., Rojas, M., Sabine, C., Shindell, D., Talley, L. D., Vaughan, D. G., and Xie, S.-P.: Technical Summary. In: Climate Change 2013: The Physical Science Basis. Contribution of Working Group I to the Fifth Assessment Report of the Intergovernmental Panel on Climate Change, edited by: Stocker, T. F., Qin, D., Plattner, G.-K., Tignor, M., Allen, S. K., Boschung, J., Nauels, A., Xia, Y., Bex, V., and Midgley, P. M., Cambridge University Press, Cambridge, UK and New York, NY, USA, 2013.
Storer, R. L. and van den Heever, S. C.: Microphysical Processes Evident in Aerosol Forcing of Tropical Deep Convective Clouds, J. Atmos. Sci., 70, 430-446, 2013.

Tao, W.-K., Chen, J.-P., Li, Z., Wang, C., and Zhang, C.: Impact of aerosols on convective clouds and precipitation, Rev. Geophys., 50, RG2001, doi:10.1029/2011RG000369, 2012.

Varnai, T. and Marshak, A.: MODIS observations of enhanced clear sky reflectance near clouds, Geophys. Res. Lett., 36, L06807, doi:10.1029/2008GL037089, 2009.

Veihelmann, B. and Veefkind, J. P.: http://projects.knmi.nl/omi/ research/product/aerosol/omaero_Readme.pdf (last access: 10 May 2016), 2009.

Veihelmann, B., Levelt, P. F., Stammes, P., and Veefkind, J. P.: Simulation study of the aerosol information content in OMI spectral reflectance measurements, Atmos. Chem. Phys., 7, 3115-3127, doi:10.5194/acp-7-3115-2007, 2007.

Wall, C., Zipser, E., and Liu, C.: An Investigation of the Aerosol Indirect Effect on convective Intensity Using Satellite Observations, J. Atmos. Sci., 71, 430-447, 2014.

Winker, D. M., Pelon, J., Coakley Jr., J. A., Ackerman, S. A., Charlson, R. J., Colarco, P. R., Flamant, P., Fu, Q., Hoff, R. M., Kittaka, C., Kubar, T. L., Le Treut, H., McCormick, M. P., Mégie, G., Poole, L., Powell, K., Trepte, C., Vaughan, M. A., and Wielicki, B. A.: The CALIPSO Mission: A Global 3-D View of Aerosols and Clouds. B. Am. Meteorol. Soc., 91, 1211-1229, doi:10.1175/2010BAMS3009.1, 2010.

Zhang, J., Reid, J. S., and Holben, B. N.: An analysis of potential cloud artifacts in MODIS over ocean aerosol optical thickness products, Geophys. Res. Lett., 32, L15803, doi:10.1029/2005GL023254, 2005. 